\title{
Correction to: A Range and Performance Optimized Version of the Computer-Aided Speckle Interferometry Algorithm for Real-Time Displacement-Strain Field Monitoring
}

\section{Keene ${ }^{1}$ (1)}

Published online: 16 December 2021

(c) The Society for Experimental Mechanics, Inc 2021

\section{Correction to: Experimental Techniques}

$$
\text { https://doi.org/10.1007/s40799-021-00520-x }
$$

This article was updated to correct the acknowledgments.

Publisher's Note Springer Nature remains neutral with regard to jurisdictional claims in published maps and institutional affiliations. 